\title{
Erratum to: Introduction
}

\author{
Gil C. Santos ${ }^{1}$
}

\section{Erratum to: Axiomathes \\ DOI 10.1007/s10516-015-9268-9}

Although the Introduction mentions Patrick Maynard's "Our Graphic Minds: Graphic Cognitive Artifacts and the New Science of Mind", this article was not published in this special issue.

Further, Jorge Marques da Silva and Elena Casetta's paper was titled as "A Tentative Evaluation of Plant Physiology's Potential to Engage in Transdisciplinary Research" in the Introduction. However, the title should read as "The Evolutionary Stages of Plant Physiology and a Plea for Transdisciplinarity" as published in the article.

The online version of the original article can be found under doi:10.1007/s10516-015-9268-9.

Gil C. Santos

gilcosan@gmail.com

1 Centre for the Philosophy of Science of the University of Lisbon (CFCUL), Lisbon, Portugal 